\title{
ACOLHENDO OUTROS CONHECIMENTOS NA FORMAÇÃO DOCENTE: Uma autobiografia a 4 mãos
}

\author{
Virginia Maria Moreira Franco Starling Luiz Barcellos ${ }^{1}$ \\ Talysson Barbosa da Silveira Pereira ${ }^{2}$
}

\begin{abstract}
RESUMO
O artigo em questão narra e reflete a experiência de uma docente e um aluno em uma IES do curso de Licenciatura em Letras, na cidade de São Gonçalo, estado do Rio de Janeiro, quando ministra a matéria Educação, Meio Ambiente e Sustentabilidade. Durante o primeiro semestre de 2019, diante da necessidade de reinventar sua práxis, reconhecendo que o que tinha aprendido na Academia não seria suficiente a fim de explorar todas as possibilidades que a matéria poderia oferecer aos alunos, toma para si alguns paradigmas, redesenha o método da primeira avaliação do grupo e, ao observar a dinâmica dos acontecimentos, tece uma reflexão acerca de quais conteúdos seriam realmente necessários para o curso de formação de professores nos dias atuais, assim como sua estratégia de aplicação. No texto, os autores definem o conceito de Transição pessoal. Poderia uma transição pessoal ser contemplada no ambiente acadêmico? Para tal reflexão, o trabalho inspira-se principalmente em Garcia $(2019 ; 2018)$ e seu trabalho acerca do cotidiano, do deslocamento dos modos hegemônicos de produção e reconhecimento de conhecimentos, além da cegueira epistemológica. Também analisa e reflete sobre todo o material coletado e vivenciado junto aos alunos da matéria anteriormente mencionada. O texto termina com mais perguntas que respostas, mas a sugestão de que se pudéssemos contemplar outros conteúdos - menos racionais - para além dos que estão sendo preteridos atualmente na formação, uma teia empática se formaria e favoreceria não só a aquisição de conhecimento, mas a formação de um novo profissional, mais capaz de atuar de forma mais integral.
\end{abstract}

Palavras-chave: autoetnografia. autoconhecimento. formação de professores.

\begin{abstract}
This article narrates and reflects the experience of a professor and one of her students at an HEI in an undergraduate course of Languages, in the city of São Gonçalo, in the state of Rio de Janeiro, while she teaches the Education, Environment and Sustainability course. During the first semester of 2019, faced with the need to reinvent her praxis, recognizing that what she had learned at the Academy would not be enough in order to explore all the possibilities that the subject could offer to students, she takes for herself some paradigms, redesigns the method from the first evaluation of the group and, observing the dynamics of the events, she reflects on what contents would really be needed for the teacher training course today, as well as their application strategy. In the text, the authors define the concept of Personal Transition. Could a personal transition be contemplated in the academic environment? For such a reflection, the work is mainly inspired by Garcia $(2019 ; 2018)$ and his work on daily life, on shifting hegemonic modes of knowledge production and recognition, in addition to epistemological blindness. It also analyzes and reflects on all the material collected and experienced with students of the previously mentioned course. The text ends with more questions than answers, but the suggestion that if we could contemplate other contents - less rational - beyond those currently being overlooked in training, an empathic web would be formed and would favor not only the acquisition of knowledge, but the rising of a new professional, more capable of acting in a more integral way.
\end{abstract}

Key words: autoethnography. self-knowledge. teacher training.

Em fevereiro de 2019, Eu, Virginia, docente do magistério superior, recebo a incumbência de ministrar a matéria Educação, Meio Ambiente e Sustentabilidade para alunos do curso de Letras. A ementa era:

Conceitos de responsabilidade social e ambiental. Atribuições que profissionais da área de Letras e Linguagens devem assumir para serem reconhecidos como socialmente e ambientalmente responsáveis. Analisar o papel individual e coletivo na

\footnotetext{
${ }^{1}$ Doutoranda PROPEd - UERJ e docente ISAT.

${ }^{2}$ Graduando em Letras - Português/Inglês.
} 
construção de uma sociedade sustentável. Agenda 21. Políticas de sustentabilidade socioambiental. (ISAT, 2019)

Gostaria de destacar a frase "Analisar o papel individual e coletivo na construção de uma sociedade sustentável". Quais seriam as ferramentas, conteúdos e sobretudo conhecimentos necessários para tal tarefa? Deveria eu pensar racionalmente ou contemplar outras áreas da formação humana? Seria possível aqui separar vida acadêmica e pessoal? Afinal, como aponta Siqueira:

Dividiu-se o território representado pelo corpo humano em inúmeros pequenos lotes
de conhecimentos (...) Em consequiência desse modelo pedagógico obsoleto
impõem-se aos estudantes cada vez mais conhecimentos técnicos oriundos das
disciplinas acadêmicas, onde as informações são expostas sem qualquer
preocupação de oferecer-lhes a necessária síntese que lhes permita melhor
compreender o ser humano biográfico. (...) A filosofia desse modelo acadêmico
acolhe o objeto e não o sujeito, o corpo e não o espírito, a quantidade e não a
qualidade, a causalidade e não a finalidade, a razão e não o sentimento, o
determinismo e não a liberdade, a essência e não a existência. O predomínio do
conhecimento fragmentado gerado pelo clássico modelo das disciplinas inviabiliza a
percepção da integralidade do ser humano, que sempre será a um só tempo
biológico, psicológico, cultural e social. Esta unidade complexa é desintegrada na
formação acadêmica que considera a disciplina como unidade de medida. Dividimos
o indivisível. (SIQUEIRA, 2002, p. 2)

Larossa em seu texto Notas sobre a experiência reflete sobre as diferenças entre conteúdo e conhecimento. Nos lembra que no idioma Espanhol, só aprendemos realmente algo quando esse algo "nos passa", nos atravessa, ou seja, vivenciamos. Ao longo dos anos, sempre me sinto desconfortável quando não me é cobrado desenvolver experiências para ensinar conteúdos que, para além de um entendimento teórico, a vivencia prática é fundamental. O conhecimento na moldura do corpo.

A partir dessa inquietação, para essa matéria, assumi como premissa dois pontos:

1) Para aprofundar conceitos e práticas tais como Ecologia, meio ambiente e sustentabilidade de maneira efetiva deveria tentar uma abordagem onde o estudo começasse pela experiência pessoal de cada aluno;

2) Todo o conteúdo da matéria seria relacionado com a as percepções pessoais sobre si mesmo, na esperança de potencializar as ações propostas;

Decidi assim que uma das avaliações seria uma apresentação individual de 15 minutos. Os alunos deveriam escolher algum hábito relacionado ao conteúdo da matéria que gostariam de mudar em si mesmos, traçar uma estratégia e metodologia para a mudança. À todo esse processo, chamaremos aqui de transição interna.

Durante ou após a tentativa - uma vez que o cronograma da ação foi determinado por cada aluno e pensado para as necessidades de cada proposta - cada aluno deveria apresentar 
seu processo, independente do estágio em que se encontrava, com o auxilio de recursos visuais, notas de diário e qualquer outro recurso que coubesse no escopo da sua proposta, destacando descobertas, dificuldades, desafios e bibliografia. O importante não era completar a tarefa, mas realizar o processo. A carpintaria exigida para romper a inércia de se permitir mudanças, ainda que benéficas. Alimentação, reciclagem, atividade física, cosméticos naturais, agricultura urbana foram alguns dos temas abordados pelos alunos.

Ao testemunhar o engajamento dos alunos, Virginia reflete sobre dois pontos:

- É possível criar uma metodologia para a transição?

- É possível a ecologia de saberes (SANTOS, 2007) dentro do ambiente acadêmico, em particular na formação de professores?

Para expandir a reflexão, Virginia convida Talysson, um dos alunos que cursou a disciplina, para refletirem juntos. Ele disponibiliza aqui seu relato e reflexões, durante o que aqui chamamos de transição interna.

Utilizaremos alguns trechos do seu relato para entendermos o seu processo mudança de leitura de mundo, espelhando essa leitura para pensar sobre toda a dinâmica do coletivo. Eu, Talysson, sou do sexo masculino, tenho 24 anos, e na época cursava o $4^{\circ}$ período do curso de Letras Português/Inglês - Literaturas. O relato em questão fora entregue no dia 12 de dezembro de 2019.

\footnotetext{
Como requerimento para aprovação na disciplina, a ideia inicial era realizar uma mudança pessoal que ajudasse, de certa forma, o meio ambiente. Tínhamos que registrar as nossas etapas para no final do semestre apresentar ao demais integrantes da sala de aula a nossa transformação. Pensar em mudança é sempre muito complicado, pois temos que sair da nossa zona de conforto. Realizar essa mudança de comportamento e atitude pode ser encarado como algo cruel. Às vezes a relação do eu com o mundo está tão bem consolidada que é impossível imaginar qualquer perspectiva diferente. (PEREIRA, 2019)
}

No primeiro trecho do relato acima, observa-se que encaro a tarefa solicitada como um desafio a ser cumprido. No trecho a seguir, coloco-me em uma posição desconfortável frente ao pedido de mudança: "Pensar em mudança é sempre muito complicado, pois temos que sair da nossa zona de conforto." A zona de conforto, nesse caso, seria romper com a perspectiva de pesquisar e pensar somente em situações e teorias que envolvessem Literatura, Ensino e Linguística. Ao aplicar os conceitos de Goffman (1963) sobre identidade pessoal e social, constato que começo a construir uma identidade pessoal de insegurança. Para ele, "sair da zona de conforto" seria romper com a comodidade em que ele se encontra e encarar uma nova realidade com diversos desafios. Pensando em uma sala de aula com diversos outros alunos; o meio interacional e social arduamente ativo, deveria ser um espaço de trocas de conhecimentos e ideias, afastando uma possível manifestação de insegurança. 
Continuando na análise do relato, temos: "Realizar essa mudança de comportamento e atitude pode ser encarado como algo cruel.". A designação da mudança de comportamento e pensamento denominado como algo "cruel" revela um sentimento de dor sobre o convite à uma nova forma de pensar. "Às vezes a relação do eu com o mundo está tão bem consolidada que é impossível imaginar qualquer perspectiva diferente”. Eu mesmo me colocava em uma posição individual no mundo ao utilizar o pronome "eu" e ainda me enxergava pertencente a um grupo e espaço social que para mim era bem consolidado. Goffman (1963) discute que a identidade social é formada a partir de compartilhamentos de características entre um grupo. Sendo assim, se imaginar pertencente a um grupo e não conseguir imaginar-se em outra situação, comprova que o indivíduo ao considerar o self, compartilha a noção de pertencimento àquela sociedade.

Em seu artigo As políticas de formação docente e Curriculares de um curso de pedagogia: em Defesa da articulação de conhecimentos e da Produção coletiva, Garcia e Leite apontam:

Nóvoa em entrevista recente (BOTTO e NÓVOA, 2018) aponta que a instituição
escola assume um papel muitas vezes paradoxal, sendo responsável por formar os
sujeitos para se adequarem a valores e a um código normativo ao mesmo tempo em
que essa instituição é um espaçotempo de produção de práticas, conhecimentos e
valores que podem contribuir para problematizar e contestar a ordem social. Nesse
contexto característico do exercício da profissão docente e da formação de seus
saberes próprios, há que se considerar que a formação é um processo que se
confunde com a própria trajetória e com a vida dos professores (NÓVOA, 1992) e
que por sua peculiaridade os saberes docentes, bem como os fazeres, são
constantemente reelaborados ao longo da trajetória. (GARCIA; LEITE, 2019, p.
560)

Em tempos de cegueira epistemológica como defendido por Garcia (2019) e Oliveira (2007), como esperar que professores produzam ambientes de aprendizagem mais inclusivos e integrados se a formação de professores em si parece não entender tal relevância? Como levantar a suspeita que podemos performar individualmente dentro de um coletivo, se respeitando e respeitando a performatividade (Butler 1999) do outro, sem a necessidade de atribuirmos valores como medo, dificuldade entre outros? Tornando todas a as vidas, possíveis de vivibilidade?

Santos (2007) alerta para o desperdício da pluralidade epistemológica do mundo. Garcia $(2018 ; 2019)$ reforça esse pensamento refletindo sobre o desperdício de experiências e saberes produzidos nos cotidianos pelos modos hegemônicos de produção e reconhecimento de conhecimentos, modos esses intrínsecos na concepção moderna de escola. Quem se beneficia com os conteúdos valorizados na formação de professores atualmente? Quem se beneficiaria com um deslocamento desses conteúdos? 
Oliveira (2007) ressalta que partimos da premissa de que os desperdícios não são voluntários, mas, acontecem pela influência das lógicas de reconhecimento daquilo que é considerado válido como conhecimento pelo pensamento hegemônico e são fortemente influenciados pelo entendimento cientificista da produção de conhecimento.

Entendemos que currículos são espaços de produção de conhecimentos que trazem sentidos políticos e epistemológicos e onde esses sentidos são disputados e negociados. sendo assim:

\begin{abstract}
Que experiências e saberes são comumente invisibilizados por uma forma de conhecer e reconhecer os conhecimentos herdeira de modelos universalizantes da racionalidade científica moderna que, sobretudo no processo de escolarização, influencia o olhar cultural sobre o que pode ser considerado válido enquanto conhecimento? (...) De que maneira nossa capacidade de percepção e de diálogo com o que as escolas produzem como conhecimento é afetado pela existência de um modelo epistemológico, que nega a racionalidade de outros modos de conhecer e perceber o mundo? (GARCIA; EMILIA, 2018, p. 326)
\end{abstract}

Em meio às tensões anteriormente mencionadas, embora na época não conhecêssemos o campo da Autoetnografia, hoje percebemos que durante a apresentação dos trabalhos, esta concepção apresentou-se de modo orgânico.

De acordo com Lopez (2019) a Autoetnografia aposta em uma perspectiva metodológica que favorece a reflexão nos processos de pesquisa, e a construção de um conhecimento original a partir da própria experiência pessoal. A partir de uma escrita autobiográfica se faz visível as formas como uma pessoa é concretamente afetada e as estratégias individuais que esta usa para ressignificar a crise.

Santos (2010) afirma que a possibilidade de construção da justiça social está relacionada a nossa capacidade de assumir a diversidade epistemológica do mundo, reconhecendo e lutando contra os epistemicídios naturalizados em nossa sociedade. Expandir o presente.

\footnotetext{
Para "expandir o presente" é necessário, então, viver e narrar, na perspectiva de multiplicar as experiências que se apresentam por meio das diversas formas de ser e estar no mundo. Essa expansão do presente deve então ser um tempo de experiências, pensando que as experiências são vividas por sujeitos sociais e singulares, "cuja diferença não pode ser reduzida à uniformidade, uma diferença que se mantém diferente" (Hardt; Negri, 2005, P. 139); Podemos pensar as narrativas como outras formas de viver o presente, atribuindo sentidos às experiências ao invés de desperdiçá-las, desconsiderando suas existências e validade. (CAMPOS; REIS, 2016, p. 112)
}

Para uma ecologia dos saberes é necessário expandir o presente, de preferência para além dos muros da escola. 


\section{Procedimentos metodológicos}

Nem todas as experiências quando compartilhadas se traduzem em "realidades emancipatórias" (Oliveira, 2012), mas entendemos que "o conhecimento emancipação é um conhecimento local criado e disseminado através do discurso argumentativo e que só pode haver discurso argumentativo dentro de comunidades interpretativas" (Santos, 2010, p. 95).

A Transição Interna e a Educação entrecruzam-se em um caminho investigativo através das estratégias educacionais mais livres, mais sensíveis e amplas. Consiste em perceber o sujeito como único, como um agente autotransformador. $\mathrm{O}$ fazer dessa pedagogia em um contexto de formação de professores - consiste em assumir potências lúdicas como possibilidades transformadoras. Essa formação está potencializada pela ação flexível que permite acolher-se a si mesmo, perceber-se sujeito em formação e constante transformação. Um sujeito que pensa e age com flexibilidade a partir da necessidade e da experiência com o outro.

Inspirada por Thiollent (2011) e Lopez, utilizamos neste trabalho um híbrido da pesquisa-ação e a Autoetnografia. Escolhemos assim em se tratando de uma pesquisa com base empírica que é realizada em estreita associação com uma ação ou experimento, no qual os pesquisadores e os participantes da situação estão envolvidos de modo cooperativo ou participativo.

A escolha deste método deu-se, também, pelo seu caráter instrumental, pela possibilidade de conciliar, a partir dele, dois objetivos: a produção de conhecimentos que não se restrinja a coletividade considerada na investigação, e a possibilidade de transformação dos próprios sujeitos envolvidos na ação, neste caso específico, a possibilidade de reconstrução ou afirmação de uma nova práxis, assim como, a tomada de consciência em torno da prática pessoal e consequentemente, pedagógica formal e curricular.

A pesquisa-ação se dá em torno de uma estrutura metodológica que contempla a confecção, o desenrolar e a avaliação de uma ação planejada dentro de um determinado contexto ou realidade. Esta qualidade processual da pesquisa-ação, onde as hipóteses são construídas e reconstruídas no desenrolar da própria ação, se aproxima do caráter artesanal dos experimentos e dos processos criativos desenvolvidos por práticas pedagógicas.

Para Versiani (2002) a autoetnografia é um processo que ocorre dentro de um sistema social em que permite deduzir as identidades que são formadas. E o mais importante, a coletividade está imersa nesse conjunto e permite criar uma relação direta entre o pesquisador e o objeto de estudo. Além disso, a subjetividade é outro ponto importante, a construção e 
evolução do EU, já que estamos tratando de um processo, se dissolve na escrita da autoetnografia e apresenta uma perspectiva mais próxima do real.

\title{
Apresentação e discussão dos resultados
}

\begin{abstract}
Sendo assim, após um levantamento de práticas diárias e tendo assistido ao documentário Cowspiracy, percebi que eu podia fazer uma mudança interna que poderia afetar outras pessoas através da minha prática. A redução do consumo de carne vermelha foi a minha mudança no ano de 2019. A relação familiar e no ciclo de amizade não mudou muita coisa, visto que se tratando de uma pequena revolução interna, poucos perceberam. Os meus pais, por conviverem diariamente comigo, notaram a minha falta de interesse na carne ao me alimentar, perceberam, também, pela minha preferência na carne branca (frango). (PEREIRA, 2019)
\end{abstract}

No trecho destacado acima é possível observar que há um avanço cronológico no tempo, pois o estudo dá indícios de que me arrisquei em aceitar a proposta de transformação pessoal. O fato de ter mencionado o documentário, apresenta uma relação de afeto e identificação.

Contudo, alguns trechos do relato acima chamam a atenção para entender como me relaciono com os grupos sociais em que estou inserido. Ao passo que, em um trecho anterior, já demonstra uma certa preocupação com o seu inserimento em um novo grupo (OTHERS). Para Duszak (2002, p. 1):

É natural para as pessoas fazerem uma distinção entre NÓS e OUTROS (ou ELES). Nós temos o hábito de compartilhar coisas com alguns, que são como nós, e não compartilhar coisas com os outros, que não são como nós. Mas quem somos NÓS? E quem é o OUTRO? O que é que aproxima as pessoas e o que as afastam? Nós temos algum senso que nos faz querer pertencer a uns, e não querer pertencer a outros. (DUSZAK, 2002, p. 1$)^{3}$

A preocupação inserida no início do relato transmite a questão do pertencimento. Algumas questões podemos inferir aqui para entender o que Talysson estava pensando: Será que continuarei ser aceito pelo o grupo ao qual faço parte? Ou será que serei considerado um estranho? Essas angústias e a sensação de não pertencimento retornam aos pensamentos de Goffman (1967) sobre estigma, ou seja, marcas que são postas sobre alguém que descaracteriza da identidade social formalizada. Com isso, ao ser estigmatizado, o indivíduo não conseguirá mais fluir dentro de um espectro social. Quando digo: "A relação familiar e no ciclo de amizade não mudou muita coisa, visto que se tratando de uma pequena revolução interna, poucos perceberam", denuncio a minha preocupação sobre o possível processo de estigmatização que poderia sofrer, além da exclusão social.

\footnotetext{
${ }^{3}$ It is natural for people to make the distinction between Us and Others (or Them). We have a sense of sharing things with some, who are like us, and not sharing things with others, who are unlike us. But who are we? And who is the Other? What is it that brings people together or keeps them apart? We must have reasons for wanting to belong with some, and for not wanting to belong with others.
} 
Houve um aumento significativo no consumo de legumes e verduras, com o objetivo de tentar substituir a carne. É importante enfatizar que a carne não foi totalmente excluída da minha dieta, apenas houve uma diminuição. Um calendário semanal foi criado para poder servir como um guia e servir como um registro da quantidade de vezes que eu ingeria esse alimento durante a semana. No início eu deixei de comer carne duas vezes por semana, não sentia falta e não percebi muita diferença nos afazeres diários. Sabendo que a carne é fonte primária de proteína, o problema era encontrar uma alternativa para realizar uma substituição que não fosse prejudicial. Nesse momento o verde começa a fazer parte da minha alimentação. (PEREIRA, 2019)

O objetivo desse processo de transformação pessoal sugerido por Virginia era provocar nos futuros professores a capacidade de relacionar com o outro partindo de suas próprias escolhas para uma identidade, um outro de si mesmo, a diferença não como um lugar, mas como um fluxo, diferança (Derrida, 1991). Em diferentes meios, pensar em diferentes áreas do conhecimento para ampliar o entendimento do ser em sala de aula. Entender a Educação como prática transformadora está além do aplicação de técnica no dia a dia, na verdade, é saber aproveitar situações e experiências para poder se relacionar melhor com o mundo (GARCIA, 2019). Enquanto os IEAS de formação de professores não aplicarem essa práxis, pouca coisa mudará nas escolas.

O trecho acima revela como eu me permiti passar pelo processo de transição, e ainda demonstra a minha vontade de inserir outros recursos que agreguem o projeto: "Sabendo que a carne é fonte primária de proteína, o problema era encontrar uma alternativa para realizar uma substituição que não fosse prejudicial. Nesse momento o verde começa a fazer parte da minha alimentação." (PEREIRA, 2019). A declaração da adição do verde à refeição transmite a ideia de deslocar as possibilidades, de diversidade em sua forma de agir. Desloca uma perspectiva normativa que consiste em seguir o que está sendo proposto sem poder utilizar outras ferramentas úteis.

Lembrando que a premissa inicial era a redução do consumo de carne vermelha:

O último ponto que gerava dúvida era a saúde, a parte bioquímica do meu
organismo. Procurei um médico e contei sobre a minha experiência, ele não se
contrapôs, mas requereu alguns exames apenas para monitoramento e
acompanhamento. O resultado não mostrou nenhuma alteração, quando comparado
com o exame anterior, realizado no ano de 2018 . Ou seja, a mudança foi um sucesso.
Hoje, eu continuo com essa prática, atualmente só como carne vermelha 2 vezes por
mês, ou quando há algum evento social que não oferece outra alternativa.
(PEREIRA, 2019)

Ao fim do relato, como o próprio declara, “a mudança foi um sucesso.”. Contrapondo a fala no início da narrativa com a do fechamento, observa-se que a repulsa momentânea pela mudança não o impediu de progredir em seu projeto. As preocupações sobre pertencimento, e uma possível estigmatização não foram obstáculos que o impedissem de completar os seus 
objetivos. Contrariando às políticas de currículo em voga, a transição aqui não está ligada diretamente à prática de ensino de Língua Portuguesa ou Inglesa, mas permite que o professor pense em um futuro onde conhecimentos populares e curriculares possam ser integrados, e como lidar com essas perspectivas em ambientes educacionais.

Ao observar todo o relato de Talysson, observa-se que a identidade do eu (GOFFMAN, 1963) que ele constrói através de diversas interações sociais cujo resultado vem da subjetividade em se adaptar conforme o espaço determina. Com isso, pode-se dizer que há mais uma característica que compõe essa identidade, e que ela pode influenciar outras pessoas para, quem sabe, deslocar a norma ainda mais. A desconstrução de um pensamento não é uma prática que ocorre de forma simples e rápida, ainda mais quando se trata de um grupo. Mas se existe possibilidade de diálogo, acolhimento e escuta, é totalmente possível permitir-se à mudança de perspectiva. Ou não.

Correlacionando as descobertas feitas ao longo do relato de Talysson e a dinâmica do grupo de alunos que fizeram a matéria, o longo do semestre e através da metodologia de pesquisa e estratégia escolhidas, pudemos observar os seguintes fatos:

- Os alunos escolheram os temas de forma rápida. Era claro para eles o que os incomodava;

- Uma vez que cada aluno estabeleceu seu cronograma de ação, não foi observado nenhum receio por partes dos alunos em buscar auxílio no que precisassem;

- Apesar das inseguranças relatadas, os alunos apoiavam-se uns nos outros para superar possíveis estagnações, fato que gerou uma teia empática;

- Durante as aulas, a medida que cada aluno compartilhava seu tema, desafios e dúvidas com o resto do grupo, tal teia empática o acolhia, oferecendo suporte, bibliografia e estratégias;

- Através de relatos, foi observado que as famílias que precisaram ser envolvidas no processo, mesmo que resistentes no início, ao final do processo estavam totalmente integradas. Não fica claro se isso de dá devido ao engajamento com o tema, o laço afetivo que a família tem com o aluno que levou a proposta ou algum outro fator;

- No dia da avaliação em si, no lugar do nervosismo comumente visto nessas datas, vimos aplausos, abraços, entusiasmo. Os alunos que, como fruto da sua transição produziram produtos, levaram em quantidade para compartilhar com todos da sala.

- Até o presente momento, a teia empática segue funcionando. Os alunos trocam dúvidas, informações, memórias e depoimentos; 
- Todos os alunos acompanhados seguem em seus processos de transição;

- Grande maioria dos alunos que atuam como docentes na educação formal já incorporaram os ensinamentos produzidos em suas práxis.

\title{
Conclusões
}

Os saberes docentes são permanentemente tensionados pela força de representações, produzidas social e culturalmente, e circulantes em discursos midiáticos, políticos, acadêmicos, narrativas imagéticas, fílmicas, entre outros que tem a escola, a educação escolar e à docência como temáticas.

Ainda é prematuro afirmar qualquer coisa sobre uma metodologia para a transição, porém é seguro sugerir que quanto mais consolidada é a teia empática - construída a partir de pontos de contato entre as trajetórias dos alunos e com o mundo - mais horizontalizada é a construção do conhecimento.

A incorporação das autoetnografias como ferramenta nos permite pensar em lógicas de formação e princípios epistemológicos e metodológicos que podem contribuir para a efetivação dos deslocamentos e impulsionar os processos formativos a partir das reflexões sobre os currículos produzidos com os professores.

Ainda sobre os deslocamentos:

\begin{abstract}
No contexto desses estudos, a noção de encontro (GARCIA, 2015) nos auxilia a pensar nos "espaçostempos" (ALVES; OLIVEIRA, 2008) de formação docente e em sua contribuição para a produção de "políticaspráticas" (OLIVEIRA, 2013) alternativas. Garcia (2015), entende que os encontros enquanto "espaçotempo" de formação fundado nos diálogos e em práticas de "com-partilhar" (GARCIA, 2015) experiências e saberes favorecem produções mais solidárias e horizontalizadas de outros-novos saberes e fazeres entre os professores. A horizontalidade e dialogicidade favorecidas por um "espaçotempo" de formação entre pares contribuiria, assim, para provocar desestabilizações e deslocamentos nos "saberesfazeres" docentes através da negociação de sentidos. Esses deslocamentos corroboram a produção de outros sentidos, saberes e práticas, na medida em que desnaturalizam os “já sabidos”. (Garcia; Emilia 2018, p. 332)
\end{abstract}

Se as "nossas cegueiras são produzidas com os contextos culturais em que vivemos." (GARCIA; EMILIA, 2018, p. 327) sugerimos que estratégias formativas como mediações didáticas e a investigação autobiográfica possam nos ajudar a deslocar e problematizar as representações de escola, do professor, e daquilo que entendemos como conhecimento e sobretudo, aprendizagem. 
Referências

BUTLER, J.. Preface. In: Gender trouble: feminism and the subversion of identity. 2. ed. New York: Routledge, 1999. p. 08-27.

CAMPOS, M. S. N. de; REIS, G. R. F. da S. Conversas entre professoras: currículos pensados/praticados e justiça cognitiva. Práxis Educacional: Vitória da Conquista v. 12, n. 21, jan/abr, 2016. p. $103-132$.

DERRIDA, J. Margens da Filosofia. Campinas, SP: Papirus, 1999.

DUSZAK, A. Us and Others: An introduction. In: DUSZAK, A. (org.). Us and Others: Social identities across languages, discourses and cultures. [S. l.]: John Benjamins B.V, 2002. v. 98, cap. Introduction, p. 1-28. ISBN 9027251185.

GARCIA, A. ; EMILIAO, S. Narrativas em redes de compartilhamento de saberes docentes: possiveis alternativas à cegueira epistemológica? Educação e Cultura Contemporânea , v. 15, p. 325345, 2018.

GARCIA, A. ; LEITE, V. As políticas de formação docente e Curriculares de um curso de pedagogia: em Defesa da articulação de conhecimentos e da Produção coletiva. Revista Formação em Movimento v.1, n.2, p.557-582, jul./dez. 2019.

GARCIA, A. ; RODRIGUES, A. C. Existir é Ordinário: mapas de resistências nos currículos e na docência. Educação e Realidade Edição eletrônica , v. 44, p. 1/e84915-20, 2019.

GARCIA, A.; ALMEIDA, A. de. O Curso de Pedagogia da FFP/UERJ: Currículo e políticas de formação. IN: FONTOURA, H. A. da (org). Pedagogia em movimento: experiências compartilhadas na Faculdade de Formação de Professores da UERJ. Niterói: Intertexto, 2018. p 13-27.

GOFFMAN, E. Stigma and social identity. 1967.

E. Stigma: Notes on the management of spoiled identity. New York: Simon \& Shuster, 1963.

INSTITUTO SUPERIOR ANÍSIO TEIXEIRA. Ementa da disciplina: Educação, Meio Ambiente e Sustentabilidade, 2019.

LARROSA, J. Notas sobre a experiência e o saber de experiência. In: Revista Brasileira de Educação. Jan/Fev/Mar/Abr, 2002, nº 19.

OLIVEIRA, I. B. Aprendendo nos/dos/com os cotidianos a ver/ler/ouvir/sentir o mundo. Revista Educação e Sociedade, Campinas, v. 28, n. 98, p. 47-72, abr. 2007.

OLIVEIRA, I. B. Contribuições de Boaventura de Sousa Santos para a reflexão curricular: princípios emancipatórios e currículos praticados/pensados. In: Revista e-curriculum, São Paulo, v.8 n.2, ago. 2012.

PEREIRA, T. B. S. Diário Pessoal. Relato sobre mudança na alimentação em 2019. Rio de Janeiro, 2019. Não publicado.

PÉREZ, O. L. . La Investigación Educativa: lente, espejo y propuesta para la acción. 1. ed. UASLP, 2009

REIS, G. R. F. S.; CAMPOS, M. S. N. Os materiais narrativos e a reconfiguração dos currículos: desafios e possibilidades. CURRÍCULO SEM FRONTEIRAS , v. 19, p. 396, 2019.

SANTOS, B. S. Para além do pensamento abissal: das linhas globais a uma ecologia de saberes. In SANTOS, B. S.; MENESES, M. P. (Orgs.). Epistemologias do Sul. São Paulo: Cortez, 2010, p. 3183.

SANTOS, B. S. A Gramática do Tempo para uma Nova Cultura. São Paulo: Cortez, 2006.

SIQUEIRA, José Eduardo. A arte perdida de cuidar. Revista Bioética, 2002. vol. 10, nº 2. 
THIOLLENT, Michel. Metodologia da pesquisa-ação. 18. ed. São Paulo: Cortez, 2011.

VERSIANI, D. B. Autoetnografia: uma alternativa conceitual. Letras de Hoje, Porto Alegre, v. 37, n. 4, p. 57-72, dez 2002. Disponível em:

https://revistaseletronicas.pucrs.br/index.php/fale/article/download/14258/9483. Acesso em: 14 nov. 2020. 